\title{
Difference in the value of arterial and end-tidal carbon dioxide tension according to different surgical positions: Does it reliably reflect ventilation-perfusion mismatch?
}

\author{
Jin Joo, Young Hee Kim, Jaemin Lee, and Jong Ho Choi \\ Department of Anesthesiology and Pain Medicine, Seoul St. Mary's Hospital, College of Medicine, The Catholic University of Korea, \\ Seoul, Korea
}

Background: Body posture, as a gravitational factor, has a clear impact on pulmonary ventilation and perfusion. In lung units with mismatched ventilation and perfusion, gas exchange and/or elimination of carbon dioxide can be impaired. In this situation, differences in the value of arterial and end-tidal carbon dioxide tension $\left[\Delta\left(\mathrm{PaCO}{ }_{2}\right.\right.$ $\left.\left.-\mathrm{P}_{\mathrm{ET}} \mathrm{CO}_{2}\right)\right]$ are expected to increase. This study was conducted to observe how $\Delta\left(\mathrm{PaCO}_{2}-\mathrm{P}_{\mathrm{ET}} \mathrm{CO}_{2}\right)$ changed according to the 3 different surgical positions, and to determine whether $\Delta\left(\mathrm{PaCO}_{2}-\mathrm{P}_{\mathrm{ET}} \mathrm{CO}_{2}\right)$ is a reliable predictor of ventilation/perfusion mismatch when a patient is in different postural positions.

Methods: Fifty-nine patients were divided into either the chronic obstructive pulmonary disease (COPD) group $(\mathrm{n}=29)$ or the non-COPD group $(\mathrm{n}=30) \cdot \mathrm{PaCO}_{2}$ and $\mathrm{P}_{\mathrm{ET}} \mathrm{CO}_{2}$ were measured during surgery in the supine, prone, and lateral decubitus positions after a 10 minute stabilization period. The $\Delta\left(\mathrm{PaCO}_{2}-\mathrm{P}_{\mathrm{ET}} \mathrm{CO}_{2}\right)$ were calculated and compared among positions.

Results: The $\Delta\left(\mathrm{PaCO}_{2}-\mathrm{P}_{\mathrm{ET}} \mathrm{CO}_{2}\right)$ decreased slightly in the prone position and increased significantly in the lateral decubitus position compared with the supine position in both groups. These patterns almost corresponded with the degree of ventilation/perfusion mismatch from the results of the radiological studies. The $\Delta\left(\mathrm{PaCO}_{2}-\mathrm{P}_{\mathrm{ET}} \mathrm{CO}_{2}\right)$ in the COPD group was significantly greater than that in the non-COPD group at all surgical positions.

Conclusions: Lateral decubitus position is associated with marked increase in $\Delta\left(\mathrm{PaCO}_{2}-\mathrm{P}_{\mathrm{ET}} \mathrm{CO}_{2}\right)$, especially in patients with COPD. The $\Delta\left(\mathrm{PaCO}_{2}-\mathrm{P}_{\mathrm{ET}} \mathrm{CO}_{2}\right)$ is a simple and reliable indicator to predict ventilation/perfusion mismatch at different surgical positions in patients with or without COPD. (Korean J Anesthesiol 2012; 63: 216-220)

Key Words: Arterial, Carbon dioxide tension, End-tidal, Position, Ventilation-perfusion ratio.

Received: February 17, 2012. Revised: 1st, March 12, 2012; 2nd, April 2, 2012. Accepted: April 12, 2012.

Corresponding author: Jaemin Lee, M.D., Ph.D., Department of Anesthesiology and Pain Medicine, Seoul St. Mary's Hospital, The Catholic University of Korea College of Medicine, 505, Banpo-dong, Seocho-gu, Seoul 137-701, Korea. Tel: 82-2-2258-2236, Fax: 82-2-537-1951, E-mail: jmlee@catholic.ac.kr

(c) This is an open-access article distributed under the terms of the Creative Commons Attribution Non-Commercial License (http:// creativecommons.org/licenses/by-nc/3.0/), which permits unrestricted non-commercial use, distribution, and reproduction in any medium, provided the original work is properly cited. 


\section{Introduction}

Pulmonary ventilation and perfusion must be well-matched for effective uptake of oxygen and elimination of carbon dioxide. This is very important in maintenance of acid-base balance and lung physiology.

Diseases leading to alterations in ventilation or perfusion cause changes in the ventilation/perfusion (V/Q) ratio; V/Q ratio increases on account of a greater value in ventilation than that of perfusion, especially in chronic obstructive pulmonary disease (COPD) [1]. In addition, ventilation and perfusion change depending on body posture, a gravitational factor, thus the degree of $\mathrm{V} / \mathrm{Q}$ mismatch is determined by body posture [2].

Meanwhile, the differences between the value of arterial oxygen tension $\left(\mathrm{PaO}_{2}\right)$ and the value of end-tidal carbon dioxide tension $\left(\mathrm{P}_{\mathrm{ET}} \mathrm{CO}_{2}\right)$ may increase because gas exchange is not efficiently achieved nor is elimination of carbon dioxide, the product of gas exchange. This exchange is not effective in lung units with $\mathrm{V} / \mathrm{Q}$ inequality produced by lung disease or body posture. This means the value of $\Delta\left(\mathrm{PaCO}_{2}-\mathrm{P}_{\mathrm{ET}} \mathrm{CO}_{2}\right)$ could be a possible indicator that reflects $\mathrm{V} / \mathrm{Q}$ inequality.

We conducted this study to investigate $\Delta\left(\mathrm{PaCO}_{2}-\mathrm{P}_{\mathrm{ET}} \mathrm{CO}_{2}\right)$ in different body positions in patients with or without lung diseases and to determine whether the value of $\Delta\left(\mathrm{PaCO}_{2}-\right.$ $\mathrm{P}_{\mathrm{ET}} \mathrm{CO}_{2}$ ) reliably reflects $\mathrm{V} / \mathrm{Q}$ inequality, depending on surgical positions by comparing it with previous studies that used radiologic isotope.

\section{Materials and Methods}

Adult patients undergoing scheduled surgeries in the prone or lateral decubitus position were enrolled from January to December, 2011. Patients were divided into 2 groups: COPD group $(n=29)$ included patients who had history of COPD and who had moderate to severe obstructive lung disease with forced expiratory volume 1 second (FEV1) less than 2.5 liter (normal range; $3.0-4.5$ liter) and the ratio of FEV1 and forced vital capacity (FVC) (FEV1/FVC) less than 60\% (normal range; 75-80\%) in preoperative pulmonary function test (PFT) [3]; the non-COPD group $(\mathrm{n}=30)$ included patients who did not have a history of lung diseases or who had normal preoperative PFT values. Patients with cardiovascular disease (hypertension, arrhythmia or myocardial ischemia), hemodynamic instability (active bleeding, hypovolemia or loss of body fluid), and low or high body mass index $\left(<16\right.$ or $\left.>30 \mathrm{~kg} / \mathrm{m}^{2}\right)$ were excluded. This study was approved by the institutional review board of our hospital, and informed consent was obtained from all study subjects.

Intraoperative monitoring included 3-lead electrocardiogram, noninvasive and invasive blood-pressure measurement, pulse oximetry measurement, expired $\mathrm{CO}_{2}$ measurement, pharyngeal temperature, and urine output. Anesthesia was induced using $2.0 \mathrm{mg} / \mathrm{kg}$ of propofol and $1.0 \mathrm{mg} / \mathrm{kg}$ of rocuronium. Following loss of consciousness, sevoflurane $\left(2-5\right.$ vol\% with $\left.100 \% \mathrm{O}_{2}\right)$ was inhaled for 90 seconds, according to the cardiovascular response of the patients, and endotracheal intubation was performed. Ventilation was mechanically controlled and tidal volume was adjusted to ideal body weight $\times 9(\mathrm{ml})$. Ideal body weight was calculated by the following formula; 50 (45.5 for female) + 0.91 (height in $\mathrm{cm}-152.4$ ). Respiration rate was fixed to $10 / \mathrm{min}$. Fresh gas flow throughout the surgery was $3 \mathrm{~L} / \mathrm{min}$ $\mathrm{N}_{2} \mathrm{O}$ and $1 \mathrm{~L} / \mathrm{min} \mathrm{O}_{2}$ using a semi-closed circuit system. A 20G catheter was inserted in the radial artery to monitor arterial pressure and to obtain blood samples for arterial blood gas analysis (ABGA). Anesthesia was maintained with sevoflurane. Muscle relaxation was achieved by intermittent rocuronium injection. During surgery, $6 \mathrm{ml} / \mathrm{kg} / \mathrm{h}$ Ringer's lactate solution was infused, and $6 \%$ hydroxyethyl starch solution of the same amount of blood loss was infused in the event of bleeding.

In the supine position, sevoflurane was controlled to maintain stable vital signs and the value of bispectral index (BIS) between 40-60. After a 10 minute stabilization period, $\mathrm{PaCO}_{2}$ and $\mathrm{P}_{\mathrm{ET}} \mathrm{CO}_{2}$ were measured. Measurement of $\mathrm{P}_{\mathrm{ET}} \mathrm{CO}_{2}$ used capnography (Philips M1026B, Philips Medizin Systeme, Boeblingen, Germany) and measurement of $\mathrm{PaCO}_{2}$ used blood gas analyzer (ABL800Flex, Radiometer, Copenhagen, Denmark). All equipment was calibrated before each surgery. After a 10 minute stabilization period to maintain stable vital signs and BIS value following a change to the lateral decubitus position or to the prone position, measurement of $\mathrm{PaCO}_{2}$ and $\mathrm{P}_{\mathrm{ET}} \mathrm{CO}_{2}$ were performed. The same frame was used for the prone position.

The value of $\Delta\left(\mathrm{PaCO}_{2}-\mathrm{P}_{\mathrm{ET}} \mathrm{CO}_{2}\right)$ was calculated from $\mathrm{PaCO}_{2}$ and $\mathrm{P}_{\mathrm{ET}} \mathrm{CO}_{2}$ obtained at each position, compared within groups, and compared between groups at different positions.

Based on our pilot study, the expected between-group difference in mean $\Delta\left(\mathrm{PaCO}_{2}-\mathrm{P}_{\mathrm{ET}} \mathrm{CO}_{2}\right)$ value in the lateral decubitus position was $5.2 \mathrm{mmHg}$ with a SD of 4.7. On the basis of $\Delta\left[\left(\mu-\mu^{\prime}\right) / \delta\right]=1.1$ (where $\mu-\mu^{\prime}=$ difference in mean and $\delta=$ $\mathrm{SD})$, the number of measurements were 14 per group, which was adequate to achieve a power of $80 \%$ with an alpha error of 0.05 .

All data were analyzed with Sigma-Stat (Version 2.03, USA). To compare demographic data between groups, chi-square test and unpaired t-test were used. The value of $\Delta\left(\mathrm{PaCO}_{2}\right.$ $-\mathrm{P}_{\mathrm{ET}} \mathrm{CO}_{2}$ ) at different positions were compared using oneway ANOVA with post hoc test with Tukey correction when significant differences were found. The unpaired t-test was used to compare the value of $\Delta\left(\mathrm{PaCO}_{2}-\mathrm{P}_{\mathrm{ET}} \mathrm{CO}_{2}\right)$ between groups in each position. A $\mathrm{P}$ value $<0.05$ was considered statistically significant. 


\section{Results}

The demographic data are shown in Table 1.

The value of $\Delta\left(\mathrm{PaCO}_{2}-\mathrm{P}_{\mathrm{ET}} \mathrm{CO}_{2}\right)$ within groups decreased in the prone position than that in the supine position, although it did not have statistical significance; the increase in the $\Delta\left(\mathrm{PaCO}_{2}-\mathrm{P}_{\mathrm{ET}} \mathrm{CO}_{2}\right)$ value to the lateral decubitus position was statistically significant (Fig. 1).

The COPD group showed significantly higher value of $\Delta\left(\mathrm{PaCO}_{2}-\mathrm{P}_{\mathrm{ET}} \mathrm{CO}_{2}\right)$ than non-COPD group in all different positions. COPD group showed greater increase in the value of $\Delta\left(\mathrm{PaCO}_{2}-\mathrm{P}_{\mathrm{ET}} \mathrm{CO}_{2}\right)$ in lateral decubitus position than in supine position, comparing to the non-COPD group (Table 2).

Table 1. Demographic Data of the Patients

\begin{tabular}{lcc}
\hline & Non-COPD group & COPD group \\
\hline Number of patients & 30 & 29 \\
Number of measurements & & \\
$\quad$ Supine & 30 & 29 \\
Prone & 16 & 15 \\
$\quad$ Lateral decubitus & 14 & 14 \\
Type of surgery (n) & & \\
Urologic surgery & 10 & 9 \\
Orthopedic hip surgery & 4 & 5 \\
Spinal surgery & $19 / 11$ & $23 / 6$ \\
Sex (M/F) & $60.7 \pm 7.4$ & $66.8 \pm 8$ \\
Age (yr) & (range; $44-76)$ & (range; $50-83$ ) \\
& $164.5 \pm 9.6$ & $167.4 \pm 8.2$ \\
Height (cm) & $64.1 \pm 9.1$ & $60.4 \pm 8.5$ \\
Weight (kg) & & $2 \pm 0.2$ \\
PFT & $3.5 \pm 0.3 *$ & $48.7 \pm 4.9$ \\
FEV1 (L) & $75.3 \pm 5.3 *$ & \\
FEV1/FVC (\%) & &
\end{tabular}

*Only 11 patients were available.

A

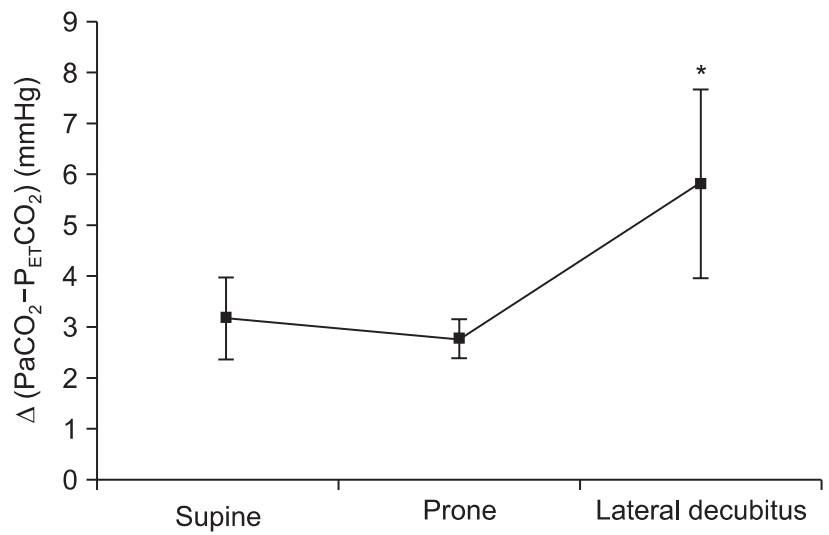

\section{Discussion}

Two classic methods of measuring pulmonary ventilation and perfusion are by radiologic isotope or by multiple inert gas elimination technique $[4,5]$. According to the previous reports using these methods, $\mathrm{V} / \mathrm{Q}$ ratio improved by approximately $15 \%$ in the prone position compared with the supine position $[6,7]$, and V/Q mismatch increases in lateral decubitus position because of increases in the shunt and dead space as a result of increased ventilation to non-dependent poorly perfused lung regions, airway closure in the dependent lung regions, and inadequate hypoxic pulmonary vasoconstriction [8].

On the other hand, it is assumed that the differences between value of $\mathrm{PaCO}_{2}$ and $\mathrm{P}_{\mathrm{ET}} \mathrm{CO}_{2}$ increase because gas exchange is not efficient and elimination of carbon dioxide, the product of gas exchange, is not effective in the lung units with $\mathrm{V} / \mathrm{Q}$ mismatch [1]. Hence, this study aimed to show how reliably $\Delta\left(\mathrm{PaCO}_{2}-\right.$ $\mathrm{P}_{\mathrm{ET}} \mathrm{CO}_{2}$ ) reflects the degree of $\mathrm{V} / \mathrm{Q}$ mismatch depending on the surgical positions.

The value of $\Delta\left(\mathrm{PaCO}_{2}-\mathrm{P}_{\mathrm{ET}} \mathrm{CO}_{2}\right)$ was smaller in prone position and greater in lateral decubitus position than in supine position, which corresponds with the degree of $\mathrm{V} / \mathrm{Q}$ inequality from the results of radiologic studies using the radiologic isotope. These results mean that the value of $\Delta\left(\mathrm{PaCO}_{2}-\mathrm{P}_{\mathrm{ET}} \mathrm{CO}_{2}\right)$ may

Table 2. Comparison of $\Delta\left(\mathrm{PaCO}_{2}-\mathrm{P}_{\mathrm{ET}} \mathrm{CO}_{2}\right)$ between Groups

\begin{tabular}{lcrc}
\hline Surgical position & Non-COPD group & COPD group & P value \\
\hline Supine & $3.2 \pm 0.82$ & $7.48 \pm 1.91$ & $<0.001$ \\
Prone & $2.8 \pm 0.38$ & $6.17 \pm 1.91$ & $<0.001$ \\
Lateral decubitus & $5.83 \pm 1.86$ & $11.41 \pm 2.67$ & $<0.001$ \\
\hline
\end{tabular}

Values are mean \pm SD (mmHg).

B

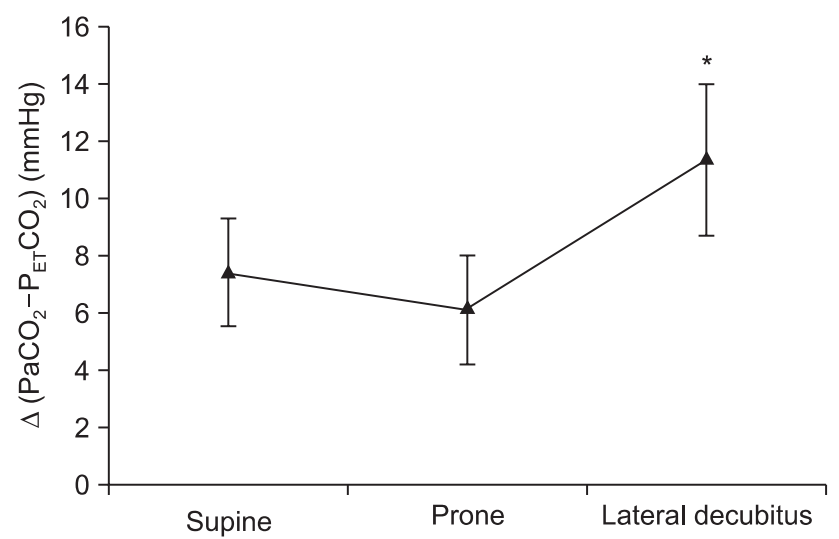

Fig. 1. Comparison of $\Delta\left(\mathrm{PaCO}_{2}-\mathrm{P}_{\mathrm{ET}} \mathrm{CO}_{2}\right)$ among surgical positions in the non-COPD group (A) and in the COPD group (B). Lateral decubitus position is associated with a statistically significantly greater $\Delta\left(\mathrm{PaCO}_{2}-\mathrm{P}_{\mathrm{ET}} \mathrm{CO}_{2}\right)$ than other positions. COPD: chronic obstructive pulmonary disease, $\mathrm{PaCO}_{2}$ : arterial carbon dioxide tension, $\mathrm{P}_{\mathrm{ET}} \mathrm{CO}_{2}$ : end-tidal carbon dioxide tension. ${ }^{*} \mathrm{P}<0.05$ vs. supine. 
be considered as an effective and simple indicator reflecting the degree of $\mathrm{V} / \mathrm{Q}$ mismatch according to different surgical positions. The value of $\Delta\left(\mathrm{PaCO}_{2}-\mathrm{P}_{\mathrm{ET}} \mathrm{CO}_{2}\right)$ was amplified in lateral decubitus position, especially in COPD group. Following explanations are possible: first, the distribution of V/Q ratios in COPD patient shows a unique broad bimodal pattern, with large amount of ventilation to lung units with extremely high $\mathrm{V} /$ $\mathrm{Q}$ ratios (alveolar dead space) [1]. The broad bimodal pattern may be augmented in the lateral decubitus position, resulting in the difference in arterial to end-tidal $\mathrm{PCO}_{2}$ to be much more significant. Second, the degree of airway closure in the dependent lung regions may be more typical in the COPD patients than in the non-COPD patients. Therefore, the value of $\Delta\left(\mathrm{PaCO}_{2}\right.$ - $\mathrm{P}_{\mathrm{ET}} \mathrm{CO}_{2}$ ) must be interpreted carefully because $\mathrm{P}_{\mathrm{ET}} \mathrm{CO}_{2}$ does not represent $\mathrm{PaCO}_{2}$ effectively owing to increased differences between the value of $\mathrm{PaCO}_{2}$ and $\mathrm{P}_{\mathrm{ET}} \mathrm{CO}_{2}$, and V/Q mismatch, as well.

Besides non-gravitational determinants, gravitational determinants such as body posture are very crucial in pulmonary blood flow and distribution of ventilation [2]. According to the reports of Shiraish et al. [9], body position has an impact on elimination of carbon dioxide, though it does not have an effect on oxygen uptake. Elimination of carbon dioxide decreases in the lateral decubitus position due to increased V/Q mismatch or decreased metabolism. Klingstedt et al. [10] reported that shunt portion and dead space increased in lateral decubitus position comparing to supine position, which resulted in increased V/Q mismatch. The increased shunt portion and dead space result in decreased $\mathrm{PaO}_{2}$, increased $\mathrm{PaCO}_{2}$ and decreased $\mathrm{P}_{\mathrm{ET}} \mathrm{CO}_{2}$. In this study, the value of $\Delta\left(\mathrm{PaCO}_{2}-\mathrm{P}_{\mathrm{ET}} \mathrm{CO}_{2}\right)$ increased in lateral decubitus position interpretably owing to V/Q mismatch, which corresponds to the studies of Klingstedt et al. and Shiraish et al. and case report of Baraka et al. [11].

In general, measuring $\mathrm{V} / \mathrm{Q}$ ratio is not easy because of the complexity of lung and experimental errors, that is, the ability of such a technique to describe the shape and position of the V/Q distribution accurately is limited [12]. The absolute and physiological values of local $\mathrm{V}$ and $\mathrm{Q}$ are not directly obtained in nuclear medicine, but indirectly through quantities to which they are supposed to be in proportion. Unfortunately, the proportionality factors for these 2 quantities are different from each other. The direct ratio of $\mathrm{V}$ and $\mathrm{Q}$ data is then lacking in absolute meaning unless an appropriate normalization is applied [13]. Hence, deciding clinical pulmonary normality or abnormality relying on classical measuring technique using nuclear medicine may lead to errors. Kjaergaard et al. [14] reported that the degree of $\mathrm{V} / \mathrm{Q}$ mismatch can be calculated by substituting non-invasive data, such as $\mathrm{FiO}_{2} / \mathrm{SaO}_{2}$ or $\mathrm{FeO}_{2} / \mathrm{SaO}_{2}$ into the mathematical model. However, this is complicated for use in clinical fields. Therefore, use of an indicator that more closely resembles the clinical situation and estimates the degree of $\mathrm{V} / \mathrm{Q}$ mismatch more conveniently is significant. Our results suggest that $\Delta\left(\mathrm{PaCO}_{2}-\mathrm{P}_{\mathrm{ET}} \mathrm{CO}_{2}\right)$ can be a convenient and reliable indicator to estimate the degree of $\mathrm{V} / \mathrm{Q}$ mismatch at different positions.

In this study, to measure the value of $\Delta\left(\mathrm{PaCO}_{2}-\mathrm{P}_{\mathrm{ET}} \mathrm{CO}_{2}\right)$, the depth of anesthesia was maintained consistently. Measurement of $\mathrm{PaCO}_{2}$ and $\mathrm{P}_{\mathrm{ET}} \mathrm{CO}_{2}$ was performed after securing stable vital signs and a BIS value after a 10 minute stabilization period in all surgical positions. Tidal volume and respiratory rate were maintained at a consistent level during anesthesia [15]. This is because the value of $\mathrm{P}_{\mathrm{ET}} \mathrm{CO}_{2}$ following positional changes is influenced by stroke volume, tidal volume, respiration rate, and functional residual capacity [16], and the stroke volume, among those factors, can be altered depending on the depth of anesthesia. The same induction and maintenance method of anesthesia was used in both groups because the shunt fraction and the degree of V/Q mismatch can be changed depending on the anesthetics used [17]. These details should be considered significantly in studying the degree of V/Q mismatch in different positions.

It requires attention in interpreting the results of this study in several ways. First, we did not measure and compare variables dividing patients into left and right lateral decubitus positions. Fujise et al. [18] reported that patients in right lateral decubitus position showed higher central venous pressure, mean blood pressure, and cardiac output than those patients in left lateral decubitus position during laparoscopic surgeries. This cannot be generalized because the patients were in a pneumoperitoneum condition for laparoscopic surgeries. However, comparing variables between left and right lateral decubitus positions is significant because blood pressure and cardiac output have effects on the value of $\mathrm{P}_{\mathrm{ET}} \mathrm{CO}_{2}$, and gas exchange alters due to greater cardiac compression and smaller volume of left lung in left lateral decubitus position compared to right lateral decubitus position [19]. Second, the data of this study were obtained under muscle relaxation and controlled positive pressure ventilation for general anesthesia so that they may differ from those under spontaneous ventilation. During spontaneous ventilation, the effect of V/Q mismatching on $\mathrm{PaCO}_{2}$ is often erroneously assumed to be negligible, and $\mathrm{PaCO}_{2}$ can usually be maintained within the normal range. This is true because the degree to which end-capillary $\mathrm{PCO}_{2}$ can be increased by gas exchange units with abnormal V/Q is relatively small due to the increased gas exchange by the units with normal V/Q ratio. Moreover, compensatory hyperventilation can maintain $\mathrm{PaCO}_{2}$ within the normal range, so the effect of $\mathrm{V} / \mathrm{Q}$ mismatching on carbon dioxide exchange can be detected by an increase in minute ventilation in patients with spontaneous ventilation [20]. Although the degree of $V / Q$ 
mismatching increases in patients under muscle relaxation and positive pressure ventilation comparing to the patients under spontaneous ventilation, data obtained under muscle relaxation and controlled positive pressure ventilation give clinically important information to the anesthesiologists.

In conclusion, the value of $\Delta\left(\mathrm{PaCO}_{2}-\mathrm{P}_{\mathrm{ET}} \mathrm{CO}_{2}\right)$ changes according to the different surgical positions, which correspond with the degree of $\mathrm{V} / \mathrm{Q}$ mismatch from the results of the radiological studies. The lateral decubitus position is associated with a marked increase in $\Delta\left(\mathrm{PaCO}_{2}-\mathrm{P}_{\mathrm{ET}} \mathrm{CO}_{2}\right)$, especially in patients with COPD, thus the value of $\mathrm{P}_{\mathrm{ET}} \mathrm{CO}_{2}$ for estimating $\mathrm{PaCO}_{2}$ should be limited in this position.

\section{References}

1. Wagner PD, West JB. Ventilation, blood flow, and gas exchange. In: Textbook of respiratory medicine. 4th ed. Edited by Mason RJ, Broaddus VC, Murray JF, Nadel JA: Philadelphia, Saunders. 2005, pp 77-82.

2. Altemeier WA, McKinney S, Krueger M, Glenny RW. Effect of posture on regional gas exchange in pigs. J Appl Physiol 2004; 97: 2104-11.

3. Thomas JG. Pulmonary function testing. In: Miller's Anesthesia. 6th ed. Edited by Miller RD: Philadelphia, Churchill-Livingstone. 2005, pp 1000-1.

4. Mure M, Nyrén S, Jacobsson H, Larsson SA, Lindahl SG. High continuous positive airway pressure level induces ventilation/ perfusion mismatch in the prone position. Crit Care Med 2001; 29: 959-64.

5. Wagner PD. Calculating the distribution of ventilation-perfusion ratios from inert gas elimination data. Fed Proc 1982; 41: 136-9.

6. Nyrén S, Radell P, Lindahl SG, Mure M, Petersson J, Larsson SA, et al. Lung ventilation and perfusion in prone and supine posture with reference to anesthetized and mechanically ventilated healthy volunteers. Anesthesiology 2010; 112: 682-7.

7. Mure M, Domino KB, Lindahl SG, Hlastala MP, Altemeier WA, Glenny RW. Regional ventilation-perfusion distribution is more uniform in the prone position. J Appl Physiol 2000; 88: 1076-83.

8. Anjou-Lindskog E, Broman L, Broman M, Holmgren A, Settergren G, Ohqvist G. Effects of intravenous anesthesia on VA/Q distribution: a study performed during ventilation with air and with 50\% oxygen, supine and in the lateral position. Anesthesiology 1985; 62: 485-92.

9. Shiraishi Y, Mizutani A, Sakai S, Tamura C, Isogaki M, Nakao Y, et al. The effects of position and ventilation during thoracotomy on oxygen uptake and carbon dioxide elimination in humans. Masui 1992; 41: 625-30.

10. Klingstedt C, Hedenstierna G, Baehrendtz S, Lundqvist H, Strandberg A, Tokics L, et al. Ventilation-perfusion relationships and atelectasis formation in the supine and lateral position during conventional mechanical and differential ventilation. Acta Anaesthesiol Scand 1990; 34: 421-9.

11. Baraka A, Moghrabi R, Yazigi A. Unilateral pulmonary oedema/ atelectasis in the lateral decubitus position. Anaesthesia 1987; 42: 171-4.

12. Ratner ER, Wagner PD. Resolution of the multiple inert gas method for estimating VA/Q maldistribution. Respir Physiol 1982; 49: 293313.

13. de Lima JJ, Botelho MF, Pereira AM, Rafael JA, Marques MA, Pinto AJ, et al. Ventilation and perfusion display in a single image. Eur J Nucl Med 1991; 18: 78-82.

14. Kjaergaard S, Rees S, Malczynski J, Nielsen JA, Thorgaard P, Toft E, et al. Non-invasive estimation of shunt and ventilation-perfusion mismatch. Intensive Care Med 2003; 29: 727-34.

15. Beck KC, Vettermann J, Rehder K. Gas exchange in dogs in the prone and supine positions. J Appl Physiol 1992; 72: 2292-7.

16. Gisolf J, Wilders R, Immink RV, van Lieshout JJ, Karemaker JM. Tidal volume, cardiac output and functional residual capacity determine end-tidal $\mathrm{CO}_{2}$ transient during standing up in humans. J Physiol 2004; 554: 579-90.

17. Dueck R, Rathbun M, Greenburg AG. Lung volume and VA/Q distribution response to intravenous versus inhalation anesthesia in sheep. Anesthesiology 1984; 61: 55-65.

18. Fujise K, Shingu K, Matsumoto S, Nagata A, Mikami O, Matsuda $\mathrm{T}$. The effects of the lateral position on cardiopulmonary function during laparoscopic urological surgery. Anesth Analg 1998; 87: 92530.

19. Dean E. Effect of body position on pulmonary function. Phys Ther 1985; 65: 613-8.

20. Moon RE, Camporesi EM. Respiratory monitoring. In: Miller's Anesthesia. 6th ed. Edited by Miller RD: Philadelphia, ChurchillLivingstone. 2005, pp 1439-40. 